\title{
Bioactivity in Whey Proteins Influencing Energy Balance
}

\author{
Liam McAllan ${ }^{1,2}$, Paul D Cotter ${ }^{1,3}$, Helen M Roche ${ }^{4}$, Riitta Korpela ${ }^{5}$ and Kanishka N Nilaweera ${ }^{1 *}$ \\ ${ }^{1}$ Teagasc Food Research Centre, Moorepark, Fermoy, Cork, Ireland \\ ${ }^{2}$ Department of Pharmacology and Therapeutics, University College Cork, Cork, Ireland \\ ${ }^{3}$ Alimentary Pharmabiotic Centre, Cork, Ireland \\ ${ }^{4}$ UCD Conway Institute of Biomolecular \& Biomedical Research, \& UCD Institute of Food \& Health, University College Dublin, Belfield Dublin 4, Ireland \\ ${ }^{5}$ Institute of Biomedicine, Biomedicum Helsinki, P.O. Box 63, Fl-00014 University of Helsinki, Finland
}

\begin{abstract}
Obesity develops due to energy (food) intake exceeding energy expenditure. Nutrients that reduce the positive energy balance are thus being considered as therapies to combat obesity. Here, we review the literature related to the physiological, cellular and endocrine effects of intake of whey proteins, namely $\alpha$-lactalbumin, $\beta$-lactoglobulin, glycomacropeptide and lactoferrin. Moreover, we discuss how dietary composition and obesity may influence whey protein effects on the above parameters. Evidence suggests that intake of whey proteins causes a decrease in energy intake, increase in energy expenditure, influence insulin sensitivity and glucose homeostasis and alter lipid metabolism in the adipose, liver and muscle. These physiological changes are accompanied by alterations in the plasma levels of energy balance related hormones (cholecystokinin, ghrelin, insulin and glucagon-like peptide-1) and the expression of catabolic and anabolic genes in the above tissue in the direction to cause a negative energy balance.
\end{abstract}

Keywords: Nutrition; Diet; Metabolic syndrome; Human; Rodent

Abbreviation: CCK: Cholecystokinin; FAS: Fatty Acid Synthase; GLP-1: Glucagon-Like Peptide-1; TAG: Triacylglycerol

\section{Introduction}

Obesity is a major health problem in the world because it increases the risk of development of several clinical conditions including cardiovascular disease, stroke, hypertension and type 2 diabetes [1]. The weight gain occurs due to storage of energy consumed in excess of daily requirement, as triacylglycerol (TAG) in the adipose tissue. The resulting increase in the mass of the adipose tissue causes the gain of weight, and it may even lead to the development of obesity [2]. The prevalence of obesity and associated co-morbidities has reached epidemic proportions globally. Hence, it is no surprise that there is a growing interest to identify therapies in particular those involving nutrients that could reduce weight gain and thus the development of obesity.

Whey is the milk serum that remains after precipitation of casein during cheese production, and it contains proteins, vitamins, minerals and trace amounts of fat. Whey associated proteins include $\alpha$-lactalbumin, $\beta$-lactoglobulin, glycomacropeptide and lactoferrin [3]. There is accumulating evidence suggesting that whey protein intake influences the balance between energy (food) intake and energy expenditure, insulin sensitivity and glucose homeostasis as well as lipid metabolism in tissues in particular in the adipose tissue. Here, we review data from in vivo (human and rodent) and in vitro studies related to the above effects of $\alpha$-lactalbumin, $\beta$-lactoglobulin, glycomacropeptide and lactoferrin and briefly discuss in the last section the actions of recently identified minor whey proteins. Furthermore, we discuss how dietary composition and obesity could influence the actions of these dietary proteins. Because authors of some of the studies mentioned below have not stated whether the whey proteins were provided as a concentrate or isolate, we have used the term "whey proteins" where this classification has not been specified.

\section{Food (Energy) Intake}

Studies conducted in humans have shown that intake of 20 to $50 \mathrm{~g}$ of whey proteins reduces short term ad libitum food intake. Akhavan et al. showed that whey protein concentrate (20-40 g) dose dependently reduces subsequent $(30 \mathrm{~min})$ ad libitum pizza meal energy intake in lean subjects, with $40 \mathrm{~g}$ having the greatest impact compared to the water control [4]. This effect extends up to $2 \mathrm{~h}$ in lean subjects [5]. In comparison to casein, whey proteins ( $48 \mathrm{~g}$ ) delay the desire to eat a subsequent meal by up to 180 mins in lean subjects [6], suggesting that the whey proteins induce satiety in comparison to casein intake. The results of rodent studies with regard to the effects of whey proteins on food (energy) intake are largely in agreement with that observed in humans. The suggestion that whey proteins induce satiety has been further confirmed in mice by showing that whey protein isolate providing 30\% energy increased intermeal interval (satiety) compared to soy protein during the 7 day period of the study [7]. Similar findings have been reported from a long term study lasting 10 weeks [8]. These data are consistent with the findings from human studies that whey proteins reduce food intake by inducing satiety in the lean state. However, a functional relationship between whey proteins and food intake has not been consistently reported. For instance, although Hall et al. showed that whey proteins reduce food intake compared to casein in humans [6], this response was not observed in rats given a whey protein isolate in comparison to casein diet $(300 \mathrm{~g} / \mathrm{kg}$ diet) for 7 weeks, despite the fact that the rats on the whey protein isolate diet showed a significantly reduced weight gain compared to the rats on the casein diet [9]. It is possible that physiological and neuroendocrine differences that exist between the species (humans vs. rats) may have given rise to the inconsistent effects of whey protein and casein on food intake. There is evidence that macronutrient composition in the diet could also impact upon the effect of whey proteins on food intake. Veldhorst et al. showed that a diet containing proteins, carbohydrates and fat providing 10,55 and $35 \%$ energy, respectively, reduces hunger in humans if whey

*Corresponding author: Kanishka Nilaweera, Teagasc Food Research Centre Moorepark, Fermoy, County Cork, Ireland, Tel: 00353 (0)25 42674; Fax: 00353 2542340; E-mail: kanishka.nilaweera@teagasc.ie

Received January 11, 2012; Accepted March 26, 2012; Published March 30 2012

Citation: McAllan L, Cotter PD, Roche HM, Korpela R, Nilaweera KN (2012) Bioactivity in Whey Proteins Influencing Energy Balance. J Metabolic Synd 1:107. doi:10.4172/2167-0943.1000107

Copyright: $\odot 2012$ McAllan L, et al. This is an open-access article distributed under the terms of the Creative Commons Attribution License, which permits unrestricted use, distribution, and reproduction in any medium, provided the original author and source are credited. 
proteins were included in comparison to either soy and casein [10]. Similar results have been obtained from a study conducted in rats, which showed that whey protein concentrate with energy content of $55 \%$ reduced cumulative energy intake compared to whole milk protein if the former protein had been supplied in a diet with either 35\% and $10 \%$ energy from carbohydrates and lipids, respectively, or in a diet with $45 \%$ energy solely from lipids [11]. No differences in cumulative energy intake were observed if the proteins were provided in diets with $15 \%$ and $30 \%$ energy from carbohydrates and fats, respectively. These data highlights the importance of the carbohydrate composition in the diet on whey protein effects on food intake. In addition to dietary composition, weight gain also seems to influence the effect of whey proteins on short term food intake. This is revealed by the finding that intake of whey protein isolate $(50 \mathrm{~g})$ reduced subsequent pizza intake in normal weight but not in obese subjects [12]. Similar findings have been reported by another human study [13] and in high fat diet induced obese mice [14]. In the latter case, diet induced obese mice that drank water supplemented with whey protein isolate at $100 \mathrm{~g} / \mathrm{L}$ for 11 weeks show similar energy intake to obese mice on un-supplemented water, despite the former group showing a significant decrease in body weight [14]. Thus, in addition to protein source, quality and time of consumption mentioned by Anderson et al. [5], both macronutrient composition in the diet and state of energy balance (lean vs. obese), should be considered as important factors influencing the whey protein effects on food intake.

A number of studies have attempted to identify the individual whey proteins present in the concentrate or isolate that might be causing the reduction in food intake in humans and rodents. Because glycomacropeptide has been shown to stimulate the production of the satiety hormone cholecystokinin (CCK) [15], a role for this whey protein in the regulation of food intake has been suggested. The findings of Veldhorst et al. support the latter suggestion, since it was shown that ingestion of a breakfast diet with whey protein providing $10 \%$ energy reduced lunchtime energy intake in lean subjects more than intake of a whey protein associated breakfast diet without glycomacropeptide [16]. This suggests that glycomacropeptide may reduce energy intake possibly by inducing satiety, as previously reported. This finding is not in agreement with data from several other studies performed on lean subjects with diets containing whey protein without glycomacropeptide (providing 44\% energy) [17] and whey protein diets with added glycomacropeptide $(21 \% \mathrm{w} / \mathrm{w})$ [18]. To explore the possibility that the discrepancies in the data on the effects of glycomacropeptide on food intake might be due to the variations in the degree of protein glycosylation, Keogh et al. provided $50 \mathrm{~g}$ of minimal glycosylated or glycosylated glycomacropeptide as well glycomacropeptide depleted whey protein concentrate to obese and overweight subjects and found that their subsequent lunch time meal intake was not affected by the dietary challenges [19]. The data suggest that the degree of glycosylation studied in the glycomacropeptide is not critical for the actions of this whey protein on food intake. As the above study was performed on obese or over-weight individuals that as described above appear to be less sensitive to whey protein effects on food intake, it would be interesting to find out whether the outcome on food intake would be different with lean individuals. However, taking in to account the data from human studies described above, and data from a rat study which revealed that glycomacropeptide does not impact on food intake [9], it could be argued that this whey protein does not have a significant effect on this physiological process. Utilising a similar approach as in their previous studies, Veldhorst et al. showed that breakfast diets with a-lactalbumin providing $10 \%$ or $25 \%$ energy reduces lunch time energy intake in lean subjects compared to a breakfast diet with casein, soy or whey without glycomacropeptide [20]. This data is in agreement with the results of another study [21], which together suggest an important role for $\alpha$-lactalbumin in suppression of food intake in lean humans. In addition to this whey protein, $\beta$-lactoglobulin has also been shown to influence energy intake. The study by Pichon et al. that showed data highlighting the importance of dietary composition on whey protein effects on energy intake, also tested the effects of $\beta$-lactoglobulin on energy intake in rats and found that $\beta$-lactoglobulin reduced energy intake compared to whole milk proteins [11]. In summary, consumption of whey proteins as an isolate or concentrate appears to reduce food (energy) intake in humans and rodents by inducing satiety compared to casein, soy or carbohydrates. This effect is influenced by the macronutrients in the whey protein diet and by development of obesity. In the former case, a high carbohydrate composition appears to favour the actions of whey proteins. Of the whey proteins that have been studied, data suggests an important role(s) for a-lactalbumin and $\beta$-lactoglobulin in the regulation of food (energy) intake, with no significant regulatory role for glycomacropeptide in this physiological process.

\section{Lipid Metabolism}

In over-weight or obese humans and rodents, whey proteins have been shown to improve lipid metabolism, particularly elevated plasma, adipose and hepatic TAG levels. Recently Pal et al. demonstrated that intake of whey protein isolate $(27 \mathrm{~g})$ twice daily for 12 weeks causes a reduction in fasting TAG levels in over-weight and obese subjects compared to casein intake [22]. A similar effect has also been observed in obese rats with intake of whey protein concentrate at 32\% (wt/wt) compared to $8 \%$ (wt/wt) [23]. Even at a reduced whey protein isolate content ( $24 \% \mathrm{wt} / \mathrm{wt}$ providing $18 \%$ energy), these dietary proteins reduce high fat (providing 60\% energy) diet induced weight gain and body fat in mice compared to casein intake [24]. The reduction in body weight and fat content observed by the latter study was not due to a difference in the intestinal fat absorption in the two groups. The authors thus investigated whether whey protein isolate may affect adipocyte lipid metabolism [25]. By providing the same high fat diets containing either whey protein isolate or casein for 21 weeks, it was shown that the adipocyte cross sectional area was reduced in mice fed with whey proteins compared to casein. This suggests that whey proteins influence lipid metabolism in adipocytes much more than casein, although the extent of the reduction in adipocyte size may have been influenced by the fact the diets contain calcium, which is known to influence lipid metabolism in this tissue [26]. Given that the liver is also important for regulation of lipid metabolism, the same authors assessed in a separate study how the same dietary challenge may impact upon the lipid metabolism in the liver of high fat diet-induced obese mice subjected to a 7 week calorie restriction [27]. Compared to calorie restricted obese mice on the casein diet, calorie restricted obese mice on the whey protein isolate diet had reduced TAG levels in the liver. The specificity with which whey protein isolate influences hepatic lipid content has been further demonstrated (in the absence of calorie restriction) by the study by Shertzer et al. [14]. In the studies mentioned above, except for the latter, the observed effects of whey protein on lipid metabolism were shown relative to casein. Interestingly, in contrast, soy proteins at $24 \%(\mathrm{wt} / \mathrm{wt})$ in the diet of rats had a similar effect on body weight and abdominal fat as whey proteins [8]. This data could be interpreted to suggest that whey protein effects on lipid metabolism are detectable only when casein is used as the control protein, or that the lack of an effect on lipid metabolism in comparison to soy might be due to the fact that the above study assessed dietary protein effects on lean rats as oppose to obese rodents, which are known to have a higher body 
weight and body fat content and thus, are likely to be more susceptible to whey protein effects on lipid metabolism. A number of studies have attempted to determine how each individual whey protein affects lipid metabolism. Two human studies show date related to the actions of lactoferrin and glycomacropeptide. By providing overweight human subjects with enteric coated lactoferrin $(100 \mathrm{mg} / \mathrm{d})$ or placebo tablets for a period of 8 weeks, it has been found that lactoferrin reduces body weight, visceral fat mass as well as hip circumference [28]. In contrast, ingestion of glycomacropeptide-enriched whey protein diet (with $15 \mathrm{~g}$ of proteins) twice daily replacing two daily meals for 6 months or once daily for further 6 months, had no significant effect on body weight or plasma TAG concentrations compared to skim milk powder diet [29]. It would be interesting to further define whether the outcome would have been different if a higher glycomacropeptide content was used, given also that data from a rodent study described below suggests an important role for this whey protein in the regulation of lipid metabolism. It has been shown that rats ingesting whey protein isolate diet supplemented with glycomacropeptide at 100 and $200 \mathrm{~g} /$ $\mathrm{kg}$ reduces carcass fat compared to in rats on a whey protein isolate diet or casein diet [9]. Because there were no differences in food intake between the groups, the data suggests a food intake-independent effect of glycomacropeptide on lipid metabolism (fat content) in these animals. With the view to assessing how other whey proteins, namely a-lactalbumin, $\beta$-lactoglobulin and lactoferrin may influence body weight and body fat content in rodents, Pilvi et al. subjected high fat diet induced obese mice to a $70 \%$ energy restricted diet containing whey protein isolate or each of the whey proteins mentioned above (18\% energy) for a period of 7 weeks to induce weight loss [30], and subsequently allowed ad libitum access to the diets for further 7 weeks to allow weight gain. Results suggest that $\alpha$ - lactalbumin is the most beneficial whey protein in terms of causing fat loss when provided as part of an energy restricted diet or fed ad libitum. Although lactoferrin caused the most weight loss and had a similar effect on percentage fat content to $\alpha$-lactalbumin in the initial 7 weeks, during the ad libitum feeding period however, lactoferrin caused the most gain in total fat content. In contrast, the human study mentioned above found that lactoferrin reduces body weight and fat content [28]. In further support for a role for lactoferrin in reducing adiposity, it has been shown in vitro that this whey protein specifically inhibits adipogenesis and lipid accumulation in adipocytes [31,32]. Although Pilvi et al. study showed that $\beta$-lactoglobulin was the least effective whey protein for inducing weight loss and for preventing weight gain [30], Pichon et al. found that $\beta$-lactoglobulin ( $55 \%$ energy) causes the least weight gain when supplemented in a diet containing only fat providing $45 \%$ of energy in comparison to a diet containing $35 \%$ and $10 \%$ energy from carbohydrates and fat or in a diet with $15 \%$ and $30 \%$ energy from the same macronutrients, respectively [11]. The data again highlights the importance of macronutrient composition on whey proteins effects on energy balance. Note here that the macronutrient composition providing the maximum whey protein effects on body weight and body fat content appear to differ from the composition that seemed to provide a greater reduction in food intake mentioned previously; in both cases however, a diet with carbohydrate and fat providing $35 \%$ and $10 \%$ energy respectively appear to be effective to bring about both changes in food intake and body weight/lipid metabolism. In summary, whey protein isolate appears to reduce body weight and lipid metabolism both in obese humans and in rodents in comparison to casein intake, with specific effects observed in the adipocytes and in the liver, although these effects appear to be influenced by macronutrient composition in the diet. Available data suggest an important role(s) for $\alpha$-lactalbumin, $\beta$-lactoglobulin, lactoferrin and glycomacropeptide in the regulation of lipid metabolism in humans and/or in rodents.

\section{Insulin Sensitivity and Glucose Homeostasis}

In healthy and overweight humans and rodents whey protein intake has been shown to cause an acute insulinotropic response. This has been shown by supplementation of whey proteins into glucose drinks or test meals, which augments postprandial insulin release, resulting in an enhancement of glucose disposal in both healthy $[33,34]$ and type2 diabetic [35] subjects. Similar effects have been seen in anesthetised mice, where gastic gavage of whey protein $(75 \mathrm{mg})$ and glucose $(75 \mathrm{mg})$ together augmented the insulin response 3 -fold and increased glucose disposal by $31 \%$ in comparison to glucose alone [36]. In addition to acute responses, prolonged whey protein intake also improves insulin sensitivity in the obese state in both rodents $[14,23,27,37,38]$ and humans [22]. Of the whey proteins that have been tested, both a-lactalbumin and glycomacropeptide have been found to increase the postprandial insulin release (in comparison to casein protein intake) with glycomacropeptide having a greater effect than whey protein isolate or a-lactalbumin [16]. Long-term glycomacropeptide intake has also been shown to improve fasting blood insulin levels in both humans [29] and rats [9]. Similarly a high protein diet (55\% kcal) with $\beta$-lactoglobulin as it source of protein was shown by Pichon et al. [11] to reduce insulin resistance and improve fasting blood insulin levels in rats to a greater extent than that of comparable high whey protein concentrate diet. The actions of $\alpha$-lactalbumin and $\beta$-lactoglobulin on insulin sensitivity and glucose homeostasis may be due to the bioactive peptides in the proteins, since several dipeptides from $\alpha$-lactalbumin and $\beta$-lactoglobulin have been found to increase glucose uptake in L6 myotubes and isolated skeletal muscles in vitro [39]. A role for lactoferrin in the regulation of glucose homeostasis has also been suggested based on the findings that circulating levels of lactoferrin correlate negatively with hyperglycemia and positively with insulin sensitivity [40], and that intake of a lactoferrin rich whey protein isolate supplemented high fat diet improves glucose tolerance in mice in comparison to high fat diet containing casein [38]. In summary, whey protein intake appears to stimulate insulin release and could improve glucose tolerance and insulin sensitivity long term, even when accompanied by high fat feeding. The available data also suggest that this effect may be a common feature of $\alpha$-lactalbumin, $\beta$-lactoglobulin, lactoferrin and glycomacropeptide, with the latter being more potent than a-lactalbumin.

\section{Energy Expenditure}

Whey protein $(18 \mathrm{~g})$ intake prior to a bout of heavy resistance training increases post-training resting energy expenditure in humans compared to carbohydrate intake [41]. Interestingly, this effect diminishes if the whey protein meal was ingested after the resistance exercise, even if the protein content in the diet was at $30 \mathrm{~g}$ [42]. The data suggest that the timing of the dietary challenge is crucial for detecting whey protein induced changes in resting energy expenditure. Intake of whey proteins also appears to increase thermogenesis, possibly because of its higher thermic effect compared to soy or casein [33]. This may possibly be due to the whey protein induced increased protein metabolism in tissues [43]. To our knowledge, of the whey proteins associated with regulation of energy balance, only a-lactalbumin has been shown to influence energy expenditure. The study by Hursel et al. which reported an effect of $\alpha$-lactalbumin (41\% energy from the protein) ingestion on lunchtime meal intake in the healthy humans, also found that this whey protein significantly increases diet-induced thermogenesis compared to intake of whole milk protein rich diet [21]. Whether $a$-lactalbumin, or any other whey protein, could influence energy expenditure in obese humans remains to be determined, although data from a rodent study clearly suggests 
such an effect; it has been shown that diet-induced obese mice drinking water supplemented with whey proteins $(100 \mathrm{~g} / \mathrm{L})$ have increased $\mathrm{O}_{2}$ consumption compared to obese mice drinking unsupplemented water [14]. In summary, compared to carbohydrates, soy and casein, intake of whey proteins appears to increase energy expenditure in lean and obese states by influencing thermogenesis and resting energy expenditure. In the latter case, the timing of the dietary challenge might be important, in particular when associated with exercise, for obtaining an effective change in this parameter linked to energy expenditure. It is tempting to suggest that the effect of whey proteins on energy expenditure might be due to the actions of $\alpha$-lactalbumin present in the whey protein isolate or concentrate, however, this may be premature given that there are no data showing whether other whey proteins could influence energy expenditure to the same extent.

\section{Cellular Activity and Endocrine System}

It is well established that the hormones CCK, ghrelin, insulin and glucagon-like peptide-1 (GLP-1) play important roles in energy balance regulation by inhibiting (CCK, insulin and GLP-1) and stimulating (ghrelin) food (energy) intake and/or by inducing a catabolic (GLP1) and anabolic (ghrelin and insulin) responses on lipid metabolism in tissues $[44,45]$. Given the effects of whey proteins on food intake and body weight, it is no surprise that whey proteins modulate these hormones. A study by Bowen et al. showed that whey protein induced decrease in energy intake in humans, is accompanied by an increased plasma level of CCK and GLP-1 and reduces levels of ghrelin [46]. These changes were noted as early as 15 mins and continued up to 180 mins after the dietary challenge, suggesting potential acute and chronic effects of whey proteins on hormonal levels. In the case of insulin, whey proteins appear to acutely increase hormone levels, but over a time, there is a notable decline. Similar effects on hormone levels have been observed in studies conducted with only lean [6] and obese subjects [13], suggesting that whey proteins modulate hormone levels independent of weight gain and that the changes are consistent with an attempt to increase catabolism. Similar data have been obtained from rodent studies. Zhou et al. showed that the reduction in food intake in lean rats on a diet supplemented with $24 \%$ (wt/wt) whey protein concentrate, is accompanied by an increased GLP-1 level in the plasma [8]. Given that both $\alpha$-lactalbumin and $\beta$-lactoglobulin have been shown to influence food (energy) intake, it would be interesting to find out whether these proteins are responsible for the observed changes in hormone levels detected in human and rodent studies.

An advantage of conducting rodent studies in comparison to human studies is that in the former case, it is possible to dissect and analyse tissues of interest to identify specific changes in expression of energy balance related genes. To our knowledge, such investigations have not been conducted to assess the impact of whey proteins on gene expression in centres of the brain important for regulation of energy balance. In contrast, there is data to suggest that whey proteins influence gene expression related to lipid metabolism in the adipocytes and in the liver cells. The study by Pilvi et al. mentioned above performed a detailed microarray analysis of gene expression in the (reduced) adipocytes of obese mice that had ingested whey proteins [25]. This analysis revealed an increased expression of several genes involved in insulin signalling pathway in the whey protein group compared to the control casein group. The microarray data also revealed an increased expression of genes for leptin and $\beta_{3}$-adrenergic receptor. Since the mass of the adipose tissue and leptin gene expression has previously been shown to be closely linked [47], the significance of the increased expression of leptin gene in adipocytes with reduced cross sectional area remains to be determined. In contrast, a potential functional relationship could exist between the reduction in the adipose tissue and increased $\beta_{3}$-adrenergic receptor expression, given that the receptor activation is known to increase hormone sensitive lipase-mediated hydrolysis of fat, increase fat oxidation and induce uncoupling proteinmediated thermogenesis $[48,49]$, all of which are likely to reduce mass of the adipose tissue. This also indicates a potential mechanism by which whey proteins could reduce adiposity. With regard to the rat liver, whey proteins have been found to reduce activity of several lipogenic enzymes including fatty acid synthase (FAS) compared to casein intake [50]. In contrast, in the muscle, FAS expression and activity was increased in response to whey protein challenge [50], possibly to reduce hepatic production of lipids and to promote synthesis of lipids in the muscle so that these could be oxidised in the mitochondria in the muscle cells to generate energy in the form of adenosine 5 ' triphosphate. With regard to the above mentioned changes in the cellular activity observed in the adipose, muscle and liver, it is important to further define how they arise by investigating the impact of the whey proteins implicated in lipid metabolism, namely $\alpha$-lactalbumin, $\beta$-lactoglobulin, lactoferrin and glycomacropeptide. In summary, in comparison to casein and carbohydrates (glucose and fructose), whey proteins appear to drive endocrine and cellular changes consistent with a catabolic effect. This is achieved by up-regulation of the production of catabolic hormones (CCK, GLP-1 and insulin), by reduction in the production of anabolic hormone ghrelin and by modulation of the expression or activity of lipogenic, lipolytic and fat oxidation related genes in the liver, adipose and in the muscle. The decrease in insulin levels observed over time with whey protein intake might be a mechanism to reduce anabolic effects of this hormone on adipocytes [45].

\section{Minor Whey Proteins}

In addition to the above mentioned whey proteins, many other lower-abundance proteins have been found within the whey fraction. Due to recent advances in milk proteomics [51,52], this list of minor whey proteins is increasing. In fact, a recent proteomic investigation of the whey fraction has found 293 unique gene products, 176 of which were newly identified in whey [52]. Although the potential energy balance related roles of these minor whey proteins have yet to be investigated, it is interesting that some of these proteins such as lipoprotein lipase, perilipin- 2 and fatty acid binding proteins 3 and 5, have defined roles in lipid metabolism and storage. Recently, a study assessed the impact of a novel whey protein isolate rich in lactoperoxidase on high fat diet induced obesity [38] and found that this diet dose-dependently reduced bodyweight, fat mass gain, hepatic lipid accumulation and improved glucose tolerance [38]. These findings again raise the energy balance related impact of minor whey proteins.

\section{Summary and Conclusions}

Overall the data suggest that whey proteins ( $\alpha$-lactalbumin and $\beta$-lactoglobulin) decrease food intake, possibly by altering the plasma levels of hormones (CCK, GLP-1, ghrelin and insulin) important for energy balance regulation. In addition, whey proteins ( $\alpha$-lactalbumin, $\beta$-lactoglobulin, lactoferrin and glycomacropeptide) also alter lipid metabolism. This may be achieved by (1) decreasing FAS gene expression and hence TAG production in the liver, (2) by increasing lipogenesis in the muscle possibly for oxidation, and (3) by increasing $\beta_{3}$-adrenergic receptor expression in the adipocytes, possibly to decrease FAS expression in this tissue. Whey protein intake ( $\alpha$-lactalbumin, $\beta$-lactoglobulin, lactoferrin and glycomacropeptide) improves insulin sensitivity and glucose tolerance, preventing high fat diet induced insulin resistance. With regard to energy expenditure, whey proteins (a-lactalbumin) increases this energy balance related parameter 
possibly by increasing protein anabolism in the tissues. As the macroand micro-nutrient (calcium) composition in the diet and obesity all influence the mechanisms involved in the regulation of energy balance, one could envisage that any changes in these mechanisms could greatly impact upon the ability of whey proteins to influence the balance between energy intake and energy expenditure. A better understanding of how specific whey proteins influence energy balance may help in the formulation of dietary interventions that could prevent or reduce obesity.

\section{Acknowledgement}

The on-going work in the area of whey protein effects on energy balance is funded by Teagasc, Ireland. The authors have no conflicts of interest. Each author listed contributed by reviewing the literature and/or by critically reviewing the manuscript.

\section{References}

1. Schelbert KB (2009) Comorbidities of obesity. Prim Care 36: 271-285

2. Hajer GR, van Haeften TW, Visseren FL (2008) Adipose tissue dysfunction in obesity, diabetes, and vascular diseases. Eur Heart J 29: 2959-2971.

3. Krissansen GW (2007) Emerging health properties of whey proteins and their clinical implications. J Am Coll Nutr 26: 713S-723S.

4. Akhavan T, Luhovyy BL, Brown PH, Cho CE, Anderson GH (2010) Effect of premeal consumption of whey protein and its hydrolysate on food intake and postmeal glycemia and insulin responses in young adults. Am J Clin Nutr 91 : 966-975.

5. Anderson GH, Tecimer SN, Shah D, Zafar TA (2004) Protein source, quantity and time of consumption determine the effect of proteins on short-term food intake in young men. J Nutr 134: 3011-3015.

6. Hall WL, Millward DJ, Long SJ, Morgan LM (2003) Casein and whey exert different effects on plasma amino acid profiles, gastrointestinal hormone secretion and appetite. Br J Nutr 89: 239-248.

7. Yu Y, South T, Huang XF (2009) Inter-meal interval is increased in mice fed a high whey, as opposed to soy and gluten, protein diets. Appetite 52: 372-379.

8. Zhou J, Keenan MJ, Losso JN, Raggio AM, Shen L, et al. (2011) Dietary whey protein decreases food intake and body fat in rats. Obesity (Silver Spring) 19: 1568-1573.

9. Royle PJ, Mclntosh GH, Clifton PM (2008) Whey protein isolate and glycomacropeptide decrease weight gain and alter body composition in male Wistar rats. Br J Nutr 100: 88-93.

10. Veldhorst MA, Nieuwenhuizen AG, Hochstenbach-Waelen A, van Vught AJ Westerterp KR, et al. (2009) Dose-dependent satiating effect of whey relative to casein or soy. Physiol Behav 96: 675-682.

11. Pichon L, Potier M, Tome D, Mikogami T, Laplaize B, et al. (2008) High-protein diets containing different milk protein fractions differently influence energy intake and adiposity in the rat. Br J Nutr 99: 739-748.

12. Bellissimo N, Desantadina MV, Pencharz PB, Berall GB, Thomas SG, et al (2008) A comparison of short-term appetite and energy intakes in normal weight and obese boys following glucose and whey-protein drinks. Int $\mathrm{J}$ Obes (Lond) 32: 362-371.

13. Bowen J, Noakes M, Clifton PM (2007) Appetite hormones and energy intake in obese men after consumption of fructose, glucose and whey protein beverages. Int J Obes (Lond) 31: 1696-1703.

14. Shertzer HG, Woods SE, Krishan M, Genter MB, Pearson KJ (2011) Dietary whey protein lowers the risk for metabolic disease in mice fed a high-fat diet. $J$ Nutr 141: 582-587.

15. Pedersen NL, Nagain-Domaine C, Mahe S, Chariot J, Roze C, et al. (2000) Caseinomacropeptide specifically stimulates exocrine pancreatic secretion in the anesthetized rat. Peptides 21: 1527-1535.

16. Veldhorst MA, Nieuwenhuizen AG, Hochstenbach-Waelen A, Westerterp KR, Engelen MP, et al. (2009) Effects of complete whey-protein breakfasts versus whey without GMP-breakfasts on energy intake and satiety. Appetite 52: 388-395.

17. Burton-Freeman BM (2008) Glycomacropeptide (GMP) is not critical to whey induced satiety, but may have a unique role in energy intake regulation through cholecystokinin (CCK). Physiol Behav 93: 379-387.
18. Lam SM, Moughan PJ, Awati A, Morton HR (2009) The influence of whey protein and glycomacropeptide on satiety in adult humans. Physiol Behav 96: 162-168.

19. Keogh JB, Woonton BW, Taylor CM, Janakievski F, Desilva K, et al. (2010) Effect of glycomacropeptide fractions on cholecystokinin and food intake. $\mathrm{Br} J$ Nutr 104: 286-290.

20. Veldhorst MA, Nieuwenhuizen AG, Hochstenbach-Waelen A, Westerterp KR Engelen MP, et al. (2009) A breakfast with alpha-lactalbumin, gelatin, or gelatin + TRP lowers energy intake at lunch compared with a breakfast with casein, soy, whey, or whey-GMP. Clin Nutr 28: 147-155.

21. Hursel R, van der Zee L, Westerterp-Plantenga MS (2010) Effects of a breakfast yoghurt, with additional total whey protein or caseinomacropeptide depletedalpha-lactalbumin-enriched whey protein, on diet-induced thermogenesis and appetite suppression. Br J Nutr 103: 775-780.

22. Pal S, Ellis V, Dhaliwal S (2010) Effects of whey protein isolate on body composition, lipids, insulin and glucose in overweight and obese individuals. Br J Nutr 104: 716-723.

23. Belobrajdic DP, McIntosh GH, Owens JA (2004) A high-whey-protein die reduces body weight gain and alters insulin sensitivity relative to red meat in wistar rats. J Nutr 134: 1454-1458.

24. Pilvi TK, Korpela R, Huttunen M, Vapaatalo H, Mervaala EM (2007) Highcalcium diet with whey protein attenuates body-weight gain in high-fat-fed C57BI/6J mice. Br J Nutr 98: 900-907.

25. Pilvi TK, Storvik M, Louhelainen M, Merasto S, Korpela R, et al. (2008) Effect of dietary calcium and dairy proteins on the adipose tissue gene expression profile in diet-induced obesity. J Nutrigenet Nutrigenomics 1: 240-251.

26. Zemel MB (2004) Role of calcium and dairy products in energy partitioning and weight management. Am J Clin Nutr 79: 907S-912S.

27. Pilvi TK, Seppanen-Laakso T, Simolin H, Finckenberg P, Huotari A, et al. (2008) Metabolomic changes in fatty liver can be modified by dietary protein and calcium during energy restriction. World J Gastroenterol 14: 4462-4472.

28. Ono T, Murakoshi M, Suzuki N, lida N, Ohdera M, et al. (2010) Potent anti-obesity effect of enteric-coated lactoferrin: decrease in visceral fat accumulation in Japanese men and women with abdominal obesity after 8-week administration of enteric-coated lactoferrin tablets. Br J Nutr 104: 1688-1695.

29. Keogh JB, Clifton P (2008) The effect of meal replacements high in glycomacropeptide on weight loss and markers of cardiovascular disease risk. Am J Clin Nutr 87: 1602-1605.

30. Pilvi TK, Harala S, Korpela R, Mervaala EM (2009) Effects of high-calcium diets with different whey proteins on weight loss and weight regain in high-fatfed C57BL/6J mice. Br J Nutr 102: 337-341.

31. Yagi M, Suzuki N, Takayama T, Arisue M, Kodama T, et al. (2008) Lactoferrin suppress the adipogenic differentiation of MC3T3-G2/PA6 cells. J Oral Sci 50 419-425.

32. Moreno-Navarrete JM, Ortega FJ, Ricart W, Fernandez-Real JM (2009) Lactoferrin increases (172Thr)AMPK phosphorylation and insulin-induced (p473Ser)AKT while impairing adipocyte differentiation. Int J Obes (Lond) 33 991-1000

33. Acheson KJ, Blondel-Lubrano A, Oguey-Araymon S, Beaumont M, Emady Azar S, et al. (2011) Protein choices targeting thermogenesis and metabolism. Am J Clin Nutr 93: 525-534.

34. Nilsson, M, Holst JJ, Bjorck IM (2007) Metabolic effects of amino acid mixtures and whey protein in healthy subjects: studies using glucose-equivalent drinks. Am J Clin Nutr 85: 996-1004.

35. Frid AH, Nilsson M, Holst JJ, Bjorck IM (2005) Effect of whey on blood glucose and insulin responses to composite breakfast and lunch meals in type 2 diabetic subjects. Am J Clin Nutr 82: 69-75.

36. Gunnarsson PT, Winzell MS, Deacon CF, Larsen MO, Jelic K, et al. (2006) Glucose-induced incretin hormone release and inactivation are differently modulated by oral fat and protein in mice. Endocrinology 147: 3173-3180.

37. Huang XF, Liu Y, Rahardjo GL, McLennan PL, Tapsell LC, et al. (2008) Effects of diets high in whey, soy, red meat and milk protein on body weight maintenance in diet-induced obesity in mice. Nutr Diet 65: S53-S59.

38. Shi J, Tauriainen E, Martonen E, Finckenberg P, Ahlroos-Lehmus A, et al. (2011) Whey protein isolate protects against diet-induced obesity and fatty live formation. Int Dairy J 21: 513-522. 
Citation: McAllan L, Cotter PD, Roche HM, Korpela R, Nilaweera KN (2012) Bioactivity in Whey Proteins Influencing Energy Balance. J Metabolic Synd 1:107. doi:10.4172/2167-0943.1000107

Page 6 of 6

39. Morifuji M, Koga J, Kawanaka K, Higuchi M (2009) Branched-chain amino acid-containing dipeptides, identified from whey protein hydrolysates, stimulate glucose uptake rate in L6 myotubes and isolated skeletal muscles. J Nutr Sci Vitaminol (Tokyo) 55: 81-86.

40. Moreno-Navarrete JM, Ortega FJ, Bassols J, Ricart W, Fernandez-Real JM (2009) Decreased circulating lactoferrin in insulin resistance and altered glucose tolerance as a possible marker of neutrophil dysfunction in type 2 diabetes. J Clin Endocrinol Metab 94: 4036-4044.

41. Hackney KJ, Bruenger AJ, Lemmer JT (2010) Timing protein intake increase energy expenditure $24 \mathrm{~h}$ after resistance training. Med Sci Sports Exerc 42 : 998-1003.

42. Benton MJ, Swan PD (2007) Effect of protein ingestion on energy expenditure and substrate utilization after exercise in middle-aged women. Int J Sport Nutr Exerc Metab 17: 544-555

43. Boirie Y, Dangin M, Gachon P, Vasson MP, Maubois JL, et al. (1997) Slow and fast dietary proteins differently modulate postprandial protein accretion. Proc Natl Acad Sci U S A 94: 14930-14935

44. Cummings DE, Overduin $\mathrm{J}$ (2007) Gastrointestinal regulation of food intake. $J$ Clin Invest 117: 13-23.

45. Nogueiras R, Lopez M, Dieguez C (2010) Regulation of lipid metabolism by energy availability: a role for the central nervous system. Obes Rev 11: 185 201.

46. Bowen J, Noakes M, Clifton PM (2006) Appetite regulatory hormone responses to various dietary proteins differ by body mass index status despite similar reductions in ad libitum energy intake. J Clin Endocrinol Metab 91: 2913-2919.

47. Galic S, Oakhill JS, Steinberg GR (2010) Adipose tissue as an endocrine organ. Mol Cell Endocrinol 316: 129-139.

48. Weyer C, Gautier JF, Danforth E Jr. (1999) Development of beta 3-adrenocepto agonists for the treatment of obesity and diabetes--an update. Diabetes Metab 25: $11-21$

49. Holm C (2003) Molecular mechanisms regulating hormone-sensitive lipase and lipolysis. Biochem Soc Trans 31: 1120-1124

50. Morifuji M, Sakai K, Sanbongi C, Sugiura K (2005) Dietary whey protein downregulates fatty acid synthesis in the liver, but upregulates it in skeletal muscle of exercise-trained rats. Nutrition 21: 1052-1058.

51. Hettinga K, van Valenber H, de Vries S, Boeren S, van Hooijdonk T, et al. (2011) The host defense proteome of human and bovine milk. PLoS One 6: e19433.

52. Le A, Barton LD, Sanders JT, Zhang Q (2011) Exploration of bovine milk proteome in colostral and mature whey using an ion-exchange approach. $J$ Proteome Res 10: 692-704.
Submit your next manuscript and get advantages of OMICS Group submissions

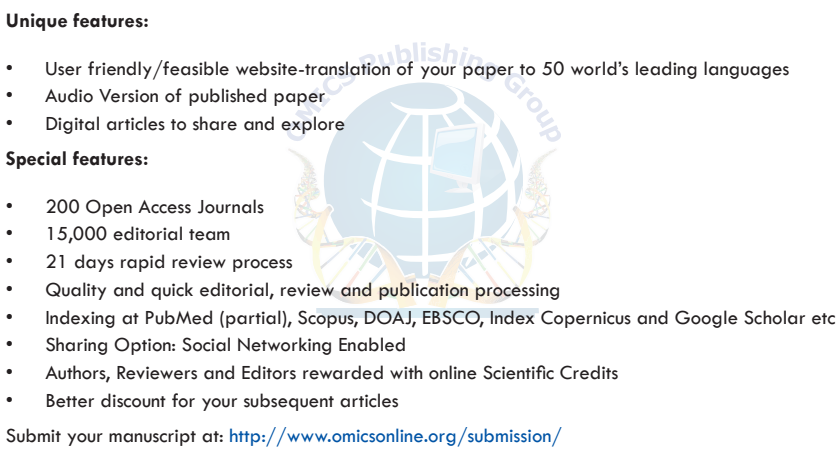

